\title{
TRAJETO
}

\section{DO TERMO}

INOVAÇÃO

\section{NOS INSTRUMENTOS}

\author{
DE AVALIAÇÃO \\ INSTITUCIONAL
}

\section{DO SINAES}

\section{CAMINO DEL TÉRMINO INNOVACIÓN EN LOS INSTRUMENTOS DE EVALUACIÓN INSTITUCIONAL DE SINAES}

\author{
PATH OF THE TERM INNOVATION IN THE INSTITUTIONAL EVALUATION INSTRUMENTS \\ OF SINAES
}

Andréia da Silva Daltoé

Dâmaris de Oliveira Batista da Silva*

Universidade do Sul de Santa Catarina

RESUMO: A palavra inovação, dirigida às universidades por órgãos reguladores do Estado, não pode ser compreendida desvinculada de sua condição material, histórica e ideológica. Ao mesmo tempo, tal condição não a torna um defeito a exigir a substituição por uma outra palavra. Procurando refletir sobre as filiações que determinam inovação nestas condições, é que objetivamos analisar o trajeto de sentidos sobre inovação nos instrumentos de avaliação institucional dirigidos pelo SINAES às universidades, a partir do referencial da Análise do Discurso de linha materialista (AD). Como corpus de análise, observamos a demanda por inovação social nos instrumentos de avaliação institucional do SINAES de 2014 e de 2017, quando da atualização do instrumento, substituindo inovação social por inovação tecnológica. Considerando que as substituições e/ou silenciamentos não

\footnotetext{
Doutorado em Letras pela Universidade Federal do Rio Grande do Sul (UFRGS); Professora do Programa de PósGraduação em Ciências da Linguagem (P PGCL) da Unisul, na linha de Texto Discurso. Líder do Grupo de Pesquisa: Relaçoes de Poder: esquecimento e memória (GREPEM-Unisul) e do Coletivo Pró-educação de Tubarão/SC; e membro do Grupode EstudosPecheutianos (GEP-UNIPAMPA). E-mail: andreia.daltoe@unisul.br.

Doutoranda do Programa de Pós-Graduação em Ciências da Linguagem (P PGCL) da Unisul, na linha de Texto Discurso. Integrante do Grupo de Pesquisa: Relaçóes de Poder: esquecimento e memória (GREPEM-Unisul). Mestre em Psicologia (UFSC-2012). Mestre em Engenharia de Produção e Sistemas (UFSC-2002). Graduação em Psicologia, Bacharel e Licenciatura (Unisul-1998).Professora Universitária (Unisul).E-mail:damarisobs@gmail.com.
} 
deixam de fazer sentido no jogo dito/não-dito, julgamos que, por meio destes documentos, é possível investigar se tal deslocamento desobriga a universidade de inovar socialmente, para levá-la apenas a produzir inovação tecnológica com vistas ao mercado. PALAVRAS-CHAVE: Discurso por Inovação. Universidade. SINAES.

RESUMEN: La palabra innovación, dirigida a las universidades por organismos reguladores del Estado, no puede ser comprendida sin vínculo con su condición material, histórica e ideológica. Al mismo tiempo, tal condición no se convierte en un defecto que exige la substitución por otra palabra. Buscando reflexionar sobre las filiaciones que determinan innovación en esas condiciones, nuestro objetivo es analizar el camino de sentidos sobre innovación en los instrumentos de evaluación institucional direccionados por SINAES a las Universidades, desde el referencial del Análisis del Discurso de línea materialista (AD). Como corpus de análisis, observamos la demanda por innovación social en los instrumentos de evaluación institucional de SINAES de 2014 y de 2017 , cuando el instrumento fue actualizado, sustituyendo innovación social por innovación tecnológica. Considerando que las substituciones y/o silencios aún hacen sentido en el juego del dicho/no-dicho, juzgamos que por medio de estos documentos es posible investigar si tal desplazamiento desobliga la Universidad de innovar socialmente para llevarla solamente a producir innovación tecnológica mirando el mercado.

PALABRAS CLAVE: Discurso por Innovación. Universidad. SINAES.

ABSTRACT: The word innovation as addressed to universities by state regulatory bodies shall not be understood unlinked to its material, historical and ideological condition. At the same time, such condition does not make it a defect requiring another word for replacement. In order to reflect on affiliations that determine innovation in such conditions, we have aimed at analyzing the path of meanings on institutional assessment instruments addressed to the universities by SINAES from the materialistic line of Discourse Analysis (DA) as referential. As a corpus of analysis, we observed requirements for social innovation on institutional assessment instruments by SINAES of 2014 and of 2017, when the instrument was updated and replaced social innovation by technological innovation. We consider the substitutions and/or silences still make sense in a said/unsaid game, we also consider that through these documents is possible investigate whether such displacement releases the university to a social innovation, to lead it to produce technological innovation with view to the market.

KEYWORDS: Discourse for Innovation. University. SINAES.

\section{INTRODUÇÃO}

Com a Constituição Federal de 1988, as universidades brasileiras tiveram prevista, no texto constitucional, a chamada autonomia universitária, o que, por sua vez, não as exime de atuarem dentro dos limites que a soberania do Estado lhes impõe. Dentre as várias regulações que definem o rumo e o papel da universidade no País, queremos neste estudo pensar o lugar do discurso por inovação que tem ganhado força desde o ano de 2014. Tomamos, então, como veiculador deste discurso o Ministério da Educação (MEC), que, por meio do Instituto Nacional de Estudos e Pesquisas Anísio Teixeira (INEP), com a Lei n ${ }^{\circ} 10.861$, de 14/04/2004, cria o Sistema Nacional de Avaliação da Educação Superior (SINAES) para "[...] para orientar sua eficácia institucional e efetividade acadêmica e social" (INEP, 2019). Como instrumento regulador, o SINAES faz uso de uma metodologia de avaliação que inclui avaliar estudantes, cursos e instituição, dentre outros aspectos.

Quanto aos instrumentos de avaliação institucional, observamos que, a partir de 2014, os critérios passaram a incluir a palavra inovação e, quando da atualização do instrumento, em 2017, tal palavra foi ampliada para outras dimensões e eixos. Por conta desta forte demanda e perguntando-nos sobre tal mudança no documento, é que este estudo visa analisar o trajeto dos sentidos sobre inovação nos instrumentos de avaliação institucional dirigidos pelo SINAES às universidades, a fim de investigar como se desenha, a partir daí, os rumos do Ensino Superior no Brasil quanto à questão.

Sob os pressupostos teórico-metodológicos da Análise de Discurso de linha materialista (AD), nosso corpus de análise será constituído pelo instrumento de avaliação institucional do SINAES, o publicado em 2014 e o atualizado em 2017, este em vigor para as universidades brasileiras até o presente momento, procurando investigar se é possível, por meio dos trajetos de inovação, compreender o papel da universidade nos tempos atuais. Deste lugar de discussão, já partimos do pressuposto de que, no discurso 
por inovação, não há, para usarmos a expressão pecheuxtiana, "inocência da fala e da escuta" ou "defeitos" (PÊCHEUX, 2008 p. 43) na forma de usar as palavras. A palavra inovação, dirigida pelo SINAES às universidades, não é descomprometida, desvinculada de uma condição material, histórica, ideológica, tampouco tal condição seria um defeito a exigir a substituição por uma outra palavra. As palavras são comprometidas com as condições de produção em que se dão e cabe-nos analisá-las exatamente em seu funcionamento.

Dito de outra forma, no discurso por inovação, há interpelação ideológica e inconsciente via linguagem que (re)organiza a universidade, (re)definindo e/ou perpetuando papéis. Paul Henry, quando analisa o discurso como instrumento ideológico da prática política, afirma que a interpelação ideológica não acontece de maneira explícita como "[...] coloque-se aqui, este é o seu lugar no sistema de produção [...]" (HENRY, 1997, p. 26), mas de maneira inconsciente, sem marcas.

Os instrumentos de avaliação, ao inserirem e ampliarem o uso de inovação, podem nos dizer sobre o processo de interpelação ideológica, que, seguindo com Henry (1997, p. 26), é apagado, mascarado, e cada um dos envolvidos vai se colocando no seu lugar, ocupando suas funções sem perceber. Para analisarmos como acontece este processo de interpelação ideológica reorganizadora dos laços sociais, lembremos que Henry trata da proposta pecheutiana na compreensão do papel da linguagem, papel que foi revisitado por meio do conceito de discurso e do entendimento de sujeito enquanto efeito ideológico (HENRY, 1997, p. 30).

Nesta filiação teórica, não podemos pensar a relação entre universidade e inovação como natural, óbvia, espontânea, dada desde sempre. Ao contrário, este posicionamento teórico nos leva a olhar para o discurso sobre inovação, tomado em sua transparência, a partir do pressuposto de que há condições materiais, históricas, complexas e contraditórias específicas que constroem as relações sociais determinantes da forma de ser e de fazer universidade de hoje. Deste lugar, problematizamos os sentidos sobre fazer inovação e ser universidade tomados como evidentes, para pensá-los como produzidos materialmente, interpelados pela ideologia e pelo inconsciente via linguagem.

\section{DO TRAJETO DOS SENTIDOS POR INOVAÇÃO}

Michel Pêcheux, na década de 60, questiona as ciências sociais de sua época e constrói uma "[...] teoria materialista dos processos discursivos [...]" (2014, p. 171). Este trabalho que se encontra, de acordo com suas palavras, "[...] definitivamente determinado por três regiões interligadas, que designaremos, respectivamente, como subjetividade, discursividade e a descontinuidade ciências/ideologias [...]" (2014, p. 122). A partir de uma tríplice fundamentação e estudos, a AD fundamenta seu trabalho: no Materialismo histórico de Karl Marx; na Psicanálise de Freud e Lacan; na Linguística de Saussure. Como teoria de entremeio, que não só trabalha com estas noções como também as problematiza, a AD vai questionar a suposta transparência da linguagem, bem como a autonomia do sujeito frente à língua. A AD, que atua na fissura, no dizer de Henry (1997, p. 14), e que trabalha no e a partir do desconforto, para lembrarmos Orlandi (2008, p.7), nos convida a questionar, a ter a "ousadia de se revoltar" contra a aparente hegemonia dos sentidos (PÊCHEUX, 2014, p. 281).

Tomar tal postura de ousadia que questiona o trajeto de sentidos de inovação dirigida às universidades é possível porque, no dizer de Orlandi (2015, p. 17), Pêcheux apreende a "não-transparência da linguagem", que vem a ser a não relação direta entre pensar e dizer/escrever. A partir dos pressupostos materialistas de que não há uma história, mas formas de narrar a história, a AD propõe tomar a língua em sua materialidade, em que forma e conteúdo são inseparáveis, em que a materialização da língua é um acontecimento em um sujeito. É o que pretendemos observar nos documentos do SINAES, tomados aqui enquanto textualidade da materialidade discursiva.

Criado em 2004, o SINAES tem uma metodologia avaliativa que envolve três componentes: avaliação do desempenho dos estudantes, avaliação dos cursos e avaliação das universidades. Tal sistema avaliativo, coordenado por uma comissão criada para este fim, a denominada Comissão Nacional de Avaliação da Educação Superior (CONAES), visa, conforme INEP (2019), "[...] traçar 
um panorama da qualidade dos cursos e instituições de educação superior no país [...]". Quanto à avaliação das universidades, o SINAES tem instrumentos para avaliação interna e avaliação externa, e ambas precisam observar as seguintes dimensões:

Missão e PDI, Política para ensino, pesquisa, pós-graduação e extensão, Responsabilidade social da IES, Comunicação com a sociedade, As políticas de pessoal, carreiras do corpo docente e de técnico-administrativo, Organização de gestão da IES, Infraestrutura física, Planejamento de avaliação, Políticas de atendimento aos estudantes, Sustentabilidade financeira. (INEP, 2019) Para operacionalizar seu objetivo, o SINAES organizou o instrumento de avaliação externa em dimensões, cada uma com seus eixos e cada eixo com seus indicadores para serem observados. Para guiar o avaliador durante a aplicação do instrumento, o indicador tem conceitos de 1 a 5, descritos como critérios de avaliação. Quanto ao instrumento de 2014, observamos que servia aos atos para credenciamento e recredenciamento. Já em 2017, o instrumento foi alterado e ampliado em dois: um para os atos de credenciamento e outro para os atos de recredenciamento.

Além das 10 dimensões anteriormente citadas, os instrumentos de 2014 e 2017 foram organizados em torno de cinco eixos: "EIXO 1 - Planejamento e Avaliação Institucional; EIXO 2 - Desenvolvimento Institucional; EIXO 3 - Políticas Acadêmicas; EIXO 4 Políticas de Gestão; EIXO 5 - Infraestrutura" (INEP, 2019). Cada eixo tem seus indicadores, e, para cada indicador, o instrumento apresenta conceitos de 1 a 5 , cada um com seu critério de análise, como podemos observar na figura a seguir:

Figura 1: Ilustração do Eixo 1, Indicador 1.1 do instrumento de 2017 para avaliação externa/recredenciamento

\section{EIXO 1 - PLANEJAMENTO E AVALIAÇÃO INSTITUCIONAL}

INDICADOR 1.1 Evolução institucional a partir dos processos de Planejamento e Avaliação Institucional

\begin{tabular}{|c|c|}
\hline CONCEITO & CRITÉRIO DE ANÁLISE \\
\hline 1 & $\begin{array}{l}\text { O Relato Institucional nåo contempla o histórico da IES, os conceitos de } \\
\text { avaliaçoes externas, o desenvolvimento e divulgaçăo dos processos de } \\
\text { autoavaliaçăo, o plano de melhorias ou os processos de geståo a partir das } \\
\text { avaliaçסes externas e internas. }\end{array}$ \\
\hline 2 & $\begin{array}{l}\text { O Relato Institucional contempla o histórico da IES, os conceitos de avaliaçōes } \\
\text { externas, o desenvolvimento e divulgaçăo dos processos de autoavaliação, o } \\
\text { plano de melhorias e os processos de gestão a partir das avaliaçóes externas e } \\
\text { internas, mas não evidencia a evoluçăo institucional. }\end{array}$ \\
\hline 3 & $\begin{array}{l}\text { O Relato Institucional demonstra a análise do histórico da IES, do conceito } \\
\text { de avaliaçōes externas, do desenvolvimento e divulgação dos processos de } \\
\text { autoavaliação, do plano de melhorias e dos processos de gestão a partir das } \\
\text { avaliaçöes externas e internas e evidencia a evoluçăo institucional. }\end{array}$ \\
\hline 4 & 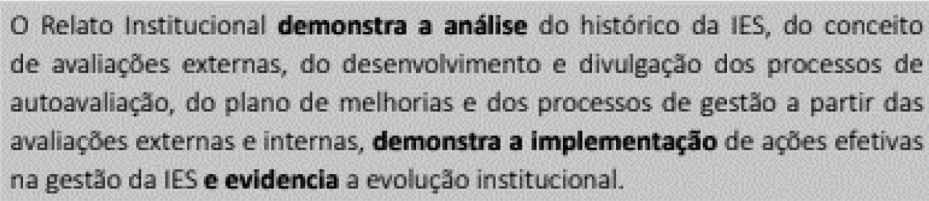 \\
\hline 5 & 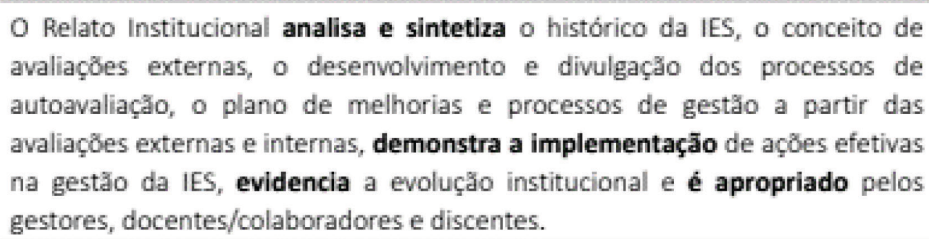 \\
\hline
\end{tabular}

Fonte: INEP (2019) 
A figura acima mostra como, na metodologia do SINAES em 2017, cada dimensão é organizada em eixos, e cada eixo tem seus indicadores. Cada indicador, por sua vez, recebe conceitos de 1 a 5, com critérios de avaliação descritos na coluna da direita.

Voltando aos instrumentos da avaliação institucional externa, observamos que, ao longo da história do SINAES, o documento é modificado periodicamente. Apesar de as dimensões e eixos terem permanecido, os indicadores e os critérios de análise foram modificados. Considerando nosso objetivo de estudo, a palavra inovação não esteve presente nos instrumentos de avaliação institucional desde a origem em 2004, tendo sido inserida nos instrumentos apenas em 2014 (INEP, 2019). Naquele ano, o termo é adjetivado como inovação social, vinculado à qualidade de vida e aos projetos sociais e, também, caracterizada como tecnológica, conforme observamos a seguir:

Figura 2: Inovação social como critério avaliativo do instrumento de avaliação externa, em 2014

\begin{tabular}{|c|l|}
\hline 5 & Quando as ações previstas/implantadas pela instituição (com ou sem \\
parceria) contemplam, de maneira excelente, o desenvolvimento econômico \\
e social, conforme proposto no PDI, considerando, em uma análise \\
sistêmica e global, os aspectos: desenvolvimento econômico regional, \\
melhoria da infraestrutura urbana/local, melhoria das condições/qualidade \\
de vida da população e projetos/ações de inovação social.
\end{tabular}

Fonte: INEP( 2019)

A figura acima é um trecho do instrumento de avaliação institucional externa do ano 2014 e apresenta o critério de avaliação que define como o conceito 5 é compreendido.

Já a figura a seguir, que apresenta a inovação tecnológica como critério avaliativo, é trecho do instrumento de avaliação externa de 2014, no qual se observa a expressão inovação tecnológica como critério avaliativo:

Figura 3: Inovação tecnológica como critério de avaliação externa, em 2014

\begin{tabular}{|c|l|}
\hline 5 & $\begin{array}{l}\text { Quando as ações previstas/implantadas pela instituição, conforme } \\
\text { proposto no PDI, contemplam a inovação tecnológica e a propriedade } \\
\text { intelectual de maneira excelente. }\end{array}$ \\
\hline
\end{tabular}

Fonte: INEP (2019)

Estas duas últimas figuras apresentadas mostram como as expressões inovação social e inovação tecnológica aparecem no instrumento de 2014.

Em outubro de 2017, quando da atualização do SINAES, o INEP ampliou o instrumento institucional para subsidiar os atos de credenciamento e os atos de recredenciamento institucional. Se antes havia um instrumento, a partir de 2017, passamos a ter dois instrumentos de avaliação institucional: inovação social foi retirada de ambos, enquanto a escrita da palavra inovação tecnológica permaneceu e foi ampliada para compor os indicadores também do Eixo Políticas Acadêmicas.

Dito de outra forma, se o SINAES foi criado para avaliar as universidades e orientar sua eficácia e sua eficiência, podemos dizer que tal intento não dependia de a instituição fazer inovação até 2014. A partir daquele ano, as universidades passaram a ter que demonstrar inovação social vinculada à qualidade de vida e aos projetos sociais e, também, inovação vinculada à tecnologia.

Trazemos um trecho do instrumento de 2017, no qual está escrita a expressão inovação tecnológica: 
Figura 4: Inovação tecnológica como critério avaliativo no Eixo de Desenvolvimento Institucional, em 2017

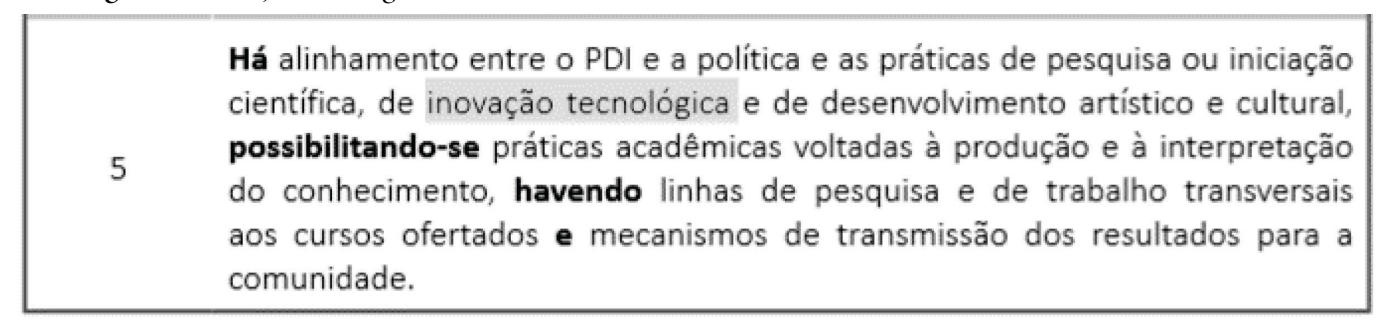

Fonte: $\operatorname{INEP}(2019)$

No trecho recortado, observamos que a expressão inovação tecnológica se apresenta como um dos meios pelos quais práticas acadêmicas poderão vir a receber o conceito 5.

A seguir, mais um trecho do instrumento de avaliação institucional para credenciamento, em que a expressão inovação tecnológica é posta como critério avaliativo no Eixo Políticas Acadêmicas:

Figura 5: Inovação tecnológica como critério avaliativo no Eixo Políticas Acadêmicas, em 2017

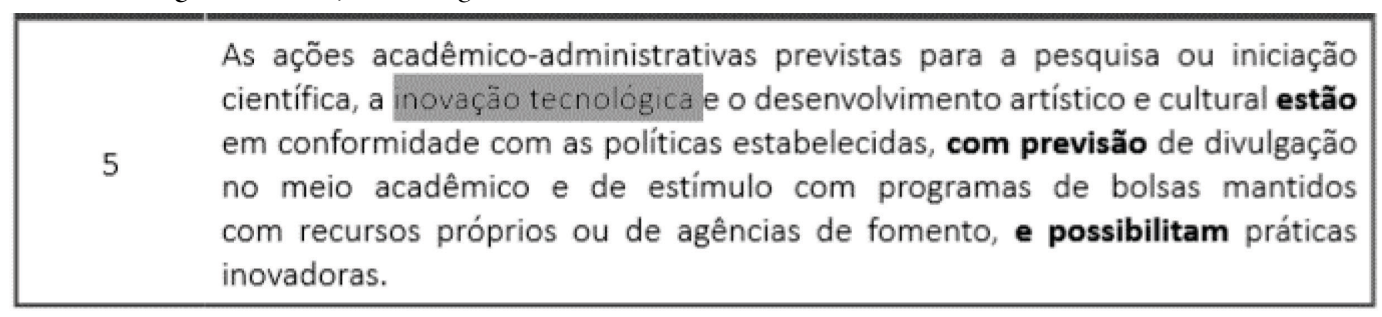

Fonte: INEP ( 2019)

Não nos deteremos, neste artigo, ao estudo dos efeitos de sentido da expressão tecnológica, assim como não verificamos se as expressões inovação social e inovação tecnológica estão operando como substantivos, como adjetivos, dentre outras possibilidades. Lembramos que nosso objetivo inicial decorre da nossa percepção de que a expressão inovação social foi silenciada no documento de 2017, enquanto inovação tecnológica foi ampliada para mais eixos avaliativos e é repetida em critérios de análise e indicadores.

Observamos que, no instrumento de avaliação institucional de 2014, que ilustramos com as figuras 2 e 3, era possível ler a expressão inovação social 6 vezes e a expressão inovação tecnológica também 6 vezes (INEP, 2019). No trajeto de leitura dos instrumentos, observamos que, em 2017, figuras 4 e 5, não localizamos a expressão inovação social, mas 26 vezes a expressão inovação tecnológica (INEP, 2019).

Se os sentidos e a relação entre inovação e universidade podem parecer evidentes e óbvios, por meio da leitura e análise que fizemos aqui, podemos observar que esta relação, no Brasil, tem uma inscrição inicial (tomamos como efeito de origem os discursos por inovação dirigidos pelo MEC às universidades somente em 2014, e modificada a partir de 2017), reconfigurando sentidos sobre inovação, universidade e o papel de ambas na sociedade.

Pensamos estar diante de processos discursivos importantes: não escrever inovação social e ampliar a inovação tecnológica no instrumento de 2017. Daí pergunta que nos fizemos: como compreender este apagamento de inovação social e sua substituição por inovação tecnológica nos instrumentos dirigidos às universidades a partir de 2017 ?

Quando da exposição da base de sua teoria materialista do discurso, Pêcheux (1996, p.143) enfatiza, em um texto bastante didático, o passo a passo para compreendermos o que ele chama de “[...] o mecanismo do (des)conhecimento ideológico [...]". Este autor, que circulava no entremeio e em pontos de ruptura, afirma que a ideologia não é o único elemento a fazer reproduzir e ou transformar as relações de produção. Chama Althusser e reafirma o papel supremo das determinações econômicas. 
Quanto à reprodução ou à transformação das relações de produção, Pêcheux faz questão de se desvincular de uma visão superficial, em que as lutas de classes se dariam a partir de uma divisão tão evidente entre o que seria reproduzir e o que seria transformar. Estes movimentos perpassam o modo de produção o tempo todo, e as ideologias, apesar da palavra, "[...] não se compõem de ideias, mas de práticas [...]" (PÊCHEUX, 1996, p. 143).

A partir de Pêcheux (1996, p. 144), afirmamos que a determinação da ideologia nos efeitos de sentido do discurso por inovação dirigido às universidades não se dá sob a forma de um zeitgeist - palavra do autor -, o espírito de uma época, uma forma de pensar homogênea e regular como um conjunto de ideias que pairassem sobre os modos de produção e as relações sociais interferindo, ditando, induzindo. Tampouco podemos atribuir uma ideologia a uma classe, como se cada classe social estivesse em um mundo de ideias à parte, coeso, coerente, preexistente. Prosseguindo com este entendimento, a ideologia dominante não atua por meio dos aparelhos ideológicos, mas existe neles, por eles e com eles, o que erige/exige um entendimento materialista à noção de ideologia. Pensando nosso corpus de estudo, um dominante ideológico se marca no sistema de avaliação para controle das universidades, com instrumentos sujeitos a atualizações contínuas e que são o meio concreto de expressar certos valores sociais e não outros de uma determinada formação social.

Para Pêcheux (1996, p. 144), a operação ideológica não é pura, no sentido de apenas reproduzir, mas seria pivô de lutas contínuas e acirradas. No entanto, neste momento da pesquisa, afirmamos que ainda não vemos o instrumento de avaliação institucional, e o próprio SINAES, como palco de lutas, revoltas e questionamentos. Não. Ao contrário. Vemos universidades federais, estaduais, privadas e comunitárias adaptando seus textos e práticas, sua missão, visão e valores inclusive, para fazerem e mostrarem a inovação demandada, sob pena de não obterem o credenciamento e/ou recredenciamento para existirem. Em nome da sobrevivência institucional, adaptam-se a este sistema ideológico dominante, cuja metodologia já parece impedir quaisquer questionamentos.

Desse modo, pode-se dizer que o SINAES, via instrumento de avaliação institucional, em seu discurso por inovação, materializa objetivos de uma sociedade neoliberal para a qual devem as universidades se transformar em espaço para invenção, aplicação, uso, produção e disseminação de tecnologias, mas não para invenção, aplicação, uso, produção e disseminação de inovação social. Parece possível poder fazer tal afirmação quando nos deparamos com a não exigência, nos instrumentos de avaliação aplicados a partir de 2017, por inovação social. O compromisso, a partir de 2017, é outro e se filia a um trajeto que visa colocar as universidades não no caminho da mudança dos dilemas sociais, mas no caminho da invenção e da construção e consumo de novos produtos e serviços de base tecnológica, que mantenham o consumismo acelerado, sinal próprio do sistema em que vivemos. Como pressuposto - e por que não dizer mensagem a ser captada -, quanto mais a universidade atender aos critérios do SINAES, melhor nota receberá; melhor mercadoria parecerá ao mercado.

Orlandi (2017, p. 216) nos lembra que, para o sistema capitalista, o trabalhador e o produto de seu trabalho são ambos transformados em mercadoria, ao mesmo tempo em que a relação entre quem faz e o que é produzido se distancia. Pensamos que a universidade, ao ser desvinculada de um compromisso com a inovação social, distancia-se das relações sociais que a formam; por outro lado, ao aproximar-se do papel de produção, consumo, invenção de tecnologia, aproxima-se do papel de uma linha de produção, prestação de serviços, formação de mão de obra, gerenciamento: uma universidade-mercadoria produzindo outras tantas mercadorias.

Dardot e Laval (2017, p.12), em seu estudo sobre Comum, afirmam que o capitalismo, por meio do seu braço neoliberal, está estendendo a lógica da concorrência a todos os níveis sociais, regulando as nossas relações no trabalho, na política e - aqui destacamos -, na educação superior. Levar as universidades a um caminho de descompromisso com a inovação social a inscreve em uma prática de silenciamento de alguns valores para o enaltecimento de outros, que se filiam a uma lógica de mercado e livre concorrência. Tal possibilidade de leitura nos mobiliza a pensar, a partir de Orlandi (2017, p. 216), Dardot e Laval (2017, p. 12), que este trajeto dos sentidos de inovação dirigidos às universidades visa orientar a educação para trabalhar para o incremento do consumismo e a acumulação do capital, sem que pese aí a preocupação com o social. São apenas palavras, poderão dizer alguns, mas, como afirma Orlandi (2017, p. 219), "[...] não somos indiferentes às palavras e as palavras não são indiferentes ao que significam [...]". Seus sentidos são possíveis porque inscritos, produzidos, geridos pelo que a autora chama de uma "[...] ideologia que é uma prática [...]" (ORLANDI, 2017, p. 219). 
Em nome de uma "educação superior de qualidade", nas palavras do INEP (2019), os instrumentos de avaliação são modificados em seus indicadores e critérios de avaliação e passam a obrigar as universidades a apresentarem relatos e práticas que atendam a estes princípios, caso queiram ser autorizadas a continuar sua existência como instituição. Não problematizaremos aqui a relação entre universidade e educação de qualidade, apenas nos deteremos inicialmente na reflexão de que a inovação tecnológica, a partir dos instrumentos de 2017, é apresentada tanto como indicador, quanto como critério de avaliação que descreve o conceito 5 (conceito máximo) para que a universidade seja reconhecida pelo INEP como universidade que faz educação de qualidade (INEP, 2019).

Continuando com a análise desta prática ideológica que transforma as universidades brasileiras, prosseguimos com Pêcheux (1996, p. 145), que nos ensina que o triunfo da ideologia dominante se materializa quando a capacidade de transformação deste cenário é suprimida, lentificada e impossibilitada. Dito de outra forma e aplicado ao nosso estudo, haveria como as universidades se negarem a participar do SINAES, do instrumento de avaliação institucional com os indicadores e critérios de avaliação na forma como estão organizados e aplicados? Parece que não, sob pena de morte enquanto instituição. Trata-se de um impedimento de se fazer universidade para outros caminhos e objetivos que não os determinados pelo sistema que nos organiza: de um capitalismo neoliberal. O instrumento de avaliação institucional em vigor desde 2017 pode ser lido como um instrumento que coíbe a inovação social voltada à qualidade de vida e aos projetos sociais. Tais critérios de avaliação, ao serem suprimidos, e a inovação tecnológica ao ser massivamente ampliada para outros eixos, indicadores, critérios e em repetidas vezes exigidas, reconfigura o ser universidade, quando esta passa a direcionar todos os esforços administrativos e pedagógicos ao atendimento dos critérios avaliativos para poder existir como instituição.

Pêcheux (1996, p. 145) afirma que há o predomínio da ideologia dominante quando a reprodução triunfa sobre a transformação. Importa repetir aqui, para efeito de aprendizagem e força à análise: triunfo da reprodução do discurso, legitimação da relação de dominação, determinação oculta aos próprios participantes - três elementos que atestam o predomínio da ideologia dominante.

Ao que nos perguntamos: o discurso por inovação dirigido pelo SINAES às universidades tem triunfado? Considerando que o resultado deste processo avaliativo é uma nota e um ato de autorização para funcionar como instituição educativa, do silenciamento, da repetição e expansão da inovação nos instrumentos dirigidos às universidades, afirmamos que sim. Triunfa quando não compreendemos que a supressão de inovação social também significa, pois, conforme Orlandi (2007, p. 102), este silenciamento se inscreve em uma política de silenciar, de fazer apagar e cindir o que pode e o que não pode, o que deve ser feito e o que não deve ser feito. Dito de outra forma, ao silenciar inovação social, o SINAES faz apagar o vínculo da universidade com aquilo que deveria ser seu norte: contribuir com a qualidade de vida a partir de sua pesquisa, de seus projetos sociais. Com Orlandi (2007, p. 102), passamos a compreender que, ao silenciar inovação social, o SINAES desobriga a universidade de ter de mostrar ao MEC suas ações nesta direção. Ao demandar muito mais inovação tecnológica, ao não constituir no instrumento inovação social, observamos a operação de uma política do silêncio: política que diz sobre a primeira e não diz sobre a segunda; política que censura, que apaga outros sentidos, apaga-os porque não pertencentes à atual conjuntura (ORLANDI, 2012, p. 128).

Trata-se de um discurso que triunfa enquanto não questionamos a "obviedade" do sentido de inovação, quando cultuamos a boa nota que a universidade alcança sem questionar a régua com que foi medida; triunfa enquanto matricularmos nossos filhos na Universidade X porque o MEC lhe atribuiu qualidade e, assim reproduzimos, contribuímos com a perpetuação da ideologia dominante cerceando as ações de ousadia e de transformação que uma universidade poderia tomar. Assim procedendo, impossibilitamos outras formas de ser e fazer universidade e prosseguimos trabalhadores anônimos da ideologia dominante que, pelo sistema de avaliação, nos conduz a todos a um projeto de desresponsabilização do social, ao mesmo tempo em que nos conduz a uma formatação tecnológica puramente rentável.

Afinal, qual instituição de ensino não quer ser inovadora? Se ousar se revoltar na trama do discurso por inovação, restaria a ela ser tomada como universidade tradicional? Neste dilema, cremos que podemos ver o ponto de encontro da interpelação ideológica, em que o sentido dominante de universidade é amalgamado ao sentido de inovação em construção pelo SINAES. Se ser universidade com qualidade é ser universidade inovadora, nos termos do SINAES, não ser universidade inovadora teria quais efeitos de sentido? 
Para a lexicógrafa Flávia Neves (2019), no site Sinônimos, os antônimos de inovadora são retrógrada, antiquada, ultrapassada, antiga, para citar alguns. Parece, então, que não há como ser universidade sem ser inovadora, no senso comum, e nos efeitos de sentido ideologicamente construídos na trama do SINAES. A interpelação da ideologia dominante convoca as universidades a uma inovação específica e estas estão a "contribuir ativamente com seu próprio assujeitamento", no dizer de Pêcheux (2015, p. 88), quando tomam por óbvio, necessário, desejado, louvável o objetivo por ser inovadora.

\section{ALGUMAS CONSIDERAÇÕES}

Universidades interpeladas pelo SINAES a assumirem o discurso inovação? Observamos que SINAES inseriu inovação como social e tecnológica. Silenciou inovação social e enfatizou tecnológica. Amarrou tudo isso a um processo de sobrevivência das universidades. E ao silenciar inovação social e a vinculação da universidade com a qualidade de vida e com os projetos sociais, SINAES trama sentidos que provocam ruptura e direcionam a universidade para o caminho neoliberal.

Nesta caminhada de leituras, buscando avaliar como os sentidos de inovação são atrelados à universidade e tomados como óbvios e evidentes, vimos que não se trata de uma demanda para qualquer inovação, mas para uma previamente definida pelo MEC: inovação social e tecnológica em 2014; inovação tecnológica de 2017. Frente ao corpus aqui analisado, observamos que a palavra inovação tem sentidos diferentes e específicos e inscreve a universidade em um projeto social reconfigurando seu papel como instituição. Junto à reflexão que fizemos, outras tantas podem surgir se desnaturalizarmos as demandas que chegam à universidade o tempo todo e questionarmos quais seus objetivos, interesses, que sociedade desenham por meio destes instrumentos, etc. Algo bastante difícil e complexo, já que tais ditames vêm junto ou com metodologias que não permitem discussões a respeito ou mesmo porque amarradas a critérios que, por fim, vão definir a nota da universidade.

A partir da $\mathrm{AD}$, compreendemos que uma palavra poderá ser a mesma em diferentes situações, mas as condições de produção as determinarão diferentemente. Compreendemos, também, que o não dizer fala, compromete, representa, participando dos mecanismos de interpelação ideológica para fazer silenciar, lentificar e suprimir.

Este trabalho iniciou uma problematização em torno da demanda por inovação dirigida às universidades nos instrumentos de avaliação institucional do SINAES e objetivou contribuir com o entendimento de que, quando vemos nossas universidades se desligando de alguns compromissos, anterior e historicamente assumidos, para voltar-se à produção, mudança e invenção de ações inovadoras de cunho tecnológico, tal percurso não é natural e próprio das universidades, tampouco seria um percurso do "espírito de uma época”, nas palavras de Pêcheux (1996, p. 144). Tal movimentação é efeito de práticas e políticas deliberadas, que operam via complexos processos de linguagem que nos interpelam ideologicamente de tal forma que o sentido de inovar passou a ser tomado como transparente e enlouquecidamente perseguido.

Todavia se, conforme Pêcheux (2014, p. 281), é preciso “ousar se revoltar" e se “[...] não há dominação sem resistência [...]”, podemos trabalhar nas rupturas do discurso avaliativo, problematizando a universidade para além de um sentido hegemônico que parece estar condicionando à existência/sobrevivência das Instituições de Educação Superior, via credenciamento e recredenciamento. A universidade é bem mais que isso: eis a nossa luta.

\section{REFERÊNCIAS}

BRASIL. Decreto $n^{\circ}$ 9235, de 15 de dezembro de 2017. Dispõe sobre o exercício das funções de regulação, supervisão e avaliação das instituições de educação superior e dos cursos superiores de graduação e de pós-graduação no sistema federal de ensino. Da Educação Superior no Sistema Federal de Ensino. Brasília, DF: Presidência da República, 2017. Disponível em: http://www.planalto.gov.br/ccivil_03/_Ato2015-2018/2017/Decreto/D9235.htm. Acesso em: 15 jul. 2019.

DARDOT, P.; LAVAL, C. Comum: ensaio sobre a revolução no século XXI. São Paulo: Boitempo, 2017. 
HENRY, P. Os fundamentos teóricos da 'Análise automática do discurso’ de Michel Pêcheux. In: GADET, Françoise; HAK, Tony (org.). Por uma análise automática do discurso: uma introdução à obra de Michel Pêcheux. 3. ed. Campinas, SP: Editora da Unicamp, 1997. p.13-38.

INSTITUTO NACIONAL DE ESTUDOS E PESQUISAS EDUCACIONAIS ANÍSIO TEIXEIRA. Instrumentos. Disponível em: http://portal.inep.gov.br/instrumentos1. Acesso em: 29 jun. 2019.

INSTITUTO NACIONAL DE ESTUDOS E PESQUISAS EDUCACIONAIS ANÍSIO TEIXEIRA. Instrumento de Avaliação Institucional Externa: subsidia os atos de credenciamento, recredenciamento e transformação da organização acadêmica (presencial). Disponível em: http://download.inep.gov.br/educacao superior/avaliacao institucional/instrumentos/2014/instrumento institucional.pdf. Acesso em: 15 jul. 2019.

INSTITUTO NACIONAL DE ESTUDOS E PESQUISAS EDUCACIONAIS ANÍSIO TEIXEIRA. Pra que serve: SINAES.

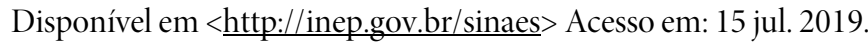

NEVES, F. Sinônimos. Disponível em: https://www.sinonimos.com.br. Acesso em: 15 fev. 2020.

ORLANDI, E. Análise de Discurso. Campinas: Pontes Editores, 2015.

ORLANDI, E. P. As formas do silêncio: no movimento dos sentidos. 6. ed. Campinas, SP: Editora da Unicamp, 2007.

ORLANDI, Eni Puccinelli (org.). Discurso e texto: formulação e circulação dos sentidos. Campinas: Pontes Editores, 2012.

ORLANDI, E. Discurso em Análise: sujeito, sentido ideologia. Campinas: Pontes Editores, 2017.

PÊCHEUX, M. O mecanismo do (des)conhecimento ideológico. In: ŽIŽEK, Slavoj (org.). Um mapa da ideologia. Rio de Janeiro: Contraponto, 1996. p.143-152.

PÊCHEUX, M. O discurso: estrutura ou acontecimento. 5. ed. Campinas, SP: Pontes Editores, 2008.

PÊCHEUX, M. Semântica e discurso: uma crítica à afirmação do óbvio. 5. ed. Campinas: Editora da Unicamp, 2014.

\section{(ㄷ) (1) $(\circledast$}

Recebido em 02/06/2020. Aceito em 08/10/2020. 